\title{
A new apterous rove beetle genus (Coleoptera: Staphylinidae) from the Northern Andes with an assessment of its phylogenetic position
}

\author{
Stylianos CHATZIMANOLIS ${ }^{1, *} \&$ Adam J. BRUNKE ${ }^{2}$ \\ ${ }^{1}$ Department of Biology, Geology and Environmental Science, University of Tennessee at \\ Chattanooga, 615 McCallie Ave. Dept 2653, Chattanooga, TN 37403, USA. \\ ${ }^{2}$ Canadian National Collection of Insects, Arachnids and Nematodes, Agriculture and Agri-Food \\ Canada, 960 Carling Avenue, K.W. Neatby Building, Ottawa, ON K1A 0C6, Canada. \\ *Corresponding author: stylianos-chatzimanolis@utc.edu \\ ${ }^{2}$ Email: adam.j.brunke@gmail.com \\ ${ }^{1}$ urn:lsid:zoobank.org:author:0BFB18A5-6424-4827-B500-DD36E99E1123 \\ ${ }^{2}$ urn:1sid:zoobank.org:author:8AEFAA65-7FA7-422C-86ED-5CD4FE611985
}

\begin{abstract}
A remarkable new apterous genus of Xanthopygina beetles is described here as Ikaros gen. nov. The new genus includes three new species, I. apteros gen. et sp. nov. from Colombia, I. paramo gen. et sp. nov. from Colombia and I. polygonos gen. et sp. nov. from Venezuela. Phylogenetic analyses using molecular and morphological data were performed to assess the phylogenetic position of Ikaros gen. nov. and whether the three new taxa formed a monophyletic group. All analyses, including those with aptery-associated characters removed, strongly supported the monophyly of Ikaros gen. nov. The genus could not be confidently resolved as a member of any of the existing genus-group lineages, likely due to a lack of morphological signal in the backbone of the tree. Further analyses, ideally with molecular data, are needed to determine the position of Ikaros gen. nov.
\end{abstract}

Keywords. Xanthopygina, Staphylinini, aptery, phylogenetics, paramo.

Chatzimanolis S. \& Brunke A.J. 2021. A new apterous rove beetle genus (Coleoptera: Staphylinidae) from the Northern Andes with an assessment of its phylogenetic position. European Journal of Taxonomy 744: 67-82. https://doi.org/10.5852/ejt.2021.744.1303

\section{Introduction}

The subtribe Xanthopygina Sharp, 1884 is a group of 30 neotropical genera in the rove beetle tribe Staphylinini Latreille, 1802. Xanthopygina are atypical within the family because they break the mould of 'little brown rove beetles': they have bright metallic colorations and they are frequently over $2 \mathrm{~cm}$ long (Chatzimanolis 2014). Almost all genera are found on rotting fruits and fungi (Chatzimanolis 2003) and actively fly between suitable microhabitats. Most genera that have been described or revised in recent years (e.g., Dysanellus Bernhauer, 1911 (Chatzimanolis 2018, 2020); Lendatus Chatzimanolis, 2019 (Chatzimanolis 2019); Peripus Chatzimanolis \& Hightower, 2019 (Chatzimanolis \& Hightower 2019); Phanolinopsis Scheerpeltz, 1968 (Chatzimanolis 2017); and Torobus Herman, 2001 (Chatzimanolis 
2018)) follow this general pattern, perhaps with the exception of Haematodes Laporte, 1835 (Brunke \& Chatzimanolis 2018), which is hypothesized to be associated with ants.

To our surprise, we recently discovered three Xanthopygina taxa in museum collections that look nothing like a typical xanthopygine: they are dull brown, have short elytra and completely lack hind wings. To our knowledge, these taxa are the only known apterous Xanthopygina rove beetles. The majority of rove beetles are peculiar among Coleoptera Linnaeus, 1758 in having elytra that do not cover their abdomen. Despite the reduced elytra, most rove beetles have fully functional hind wings, asymmetrically folded (Saito et al. 2014) underneath their elytra. While apterous rove beetles are not necessarily rare (e.g., Peng et al. 2013; Puthz 2015; Schomann \& Solodovnikov 2016; Clarke 2018; Bordoni 2020), there are few published reports of apterous Staphylinini (sec Żyła \& Solodovnikov 2020) rove beetles (Smetana 1995) but flightless species have evolved in all subtribes of Staphylinini (Brunke pers. obs.).

To test whether these three taxa form a monophyletic group and to decipher their phylogenetic position in Xanthopygina, we included these taxa into the data matrix of Chatzimanolis \& Brunke (2019) and added three morphological characters. The results of these new phylogenetic analyses are presented in this paper along with the formal descriptions of a new genus and three new species.

\section{Material and methods}

\section{Specimens}

Specimens were examined using an Olympus ZX10 stereo microscope and photographed using a Canon 40D camera equipped with a MP-E $65 \mathrm{~mm}$ macro lens on a Cognisys StackShot 3X macro rail and controller (https://cognisys-inc.com/stackshot3x-rail-pkg.html). Images were automontaged using Helicon Focus Pro ver. 7.5.6 (http://www.heliconsoft.com/heliconsoft-products/helicon-focus/).

We took the following measurements:

EL = elytra length, measured in lateral view from the anterolateral angle of the elytra to the apex of the elytra

$\mathrm{FL}=$ forebody length, a surrogate of total body length, measured by adding HL $+\mathrm{PL}+\mathrm{EL}$

$\mathrm{HL}=$ head length, at middle, from the anterior margin of frons to the nuchal ridge

HW $=$ head width, the greatest width, including the eyes

$\mathrm{PL}=$ pronotum length, at middle

$\mathrm{PW}=$ pronotum width, greatest width

We wrote the generic description based on the morphological data matrix presented in this paper. Type labels are included in quotes and separated by a slash ' $"$. Explanatory text that was not on the original label is included within square brackets [ ]. We produced the map using the online program SimpleMappr (Shorthouse 2010). In this paper, we used the phylogenetic species concept of Wheeler \& Platnick (2000) to delimit different species.

Specimens were deposited in the following collections:

IAVH = Instituto Alexander von Humboldt, Bogotá, Colombia

MIZA = Francisco Fernández Yépez Museum of the Agricultural Zoological Institute, Maracay, Venezuela

SDEI = Senckenberg Deutsches Entomologisches Institut, Müncheberg, Germany (S. Blank)

SEMC Snow Entomological Collection, Biodiversity Institute, University of Kansas, Lawrence, KS, USA (Z. Falin)

UTCI The University of Tennessee at Chattanooga, Chattanooga, TN, USA (S. Chatzimanolis) 


\section{Phylogenetic analyses}

The molecular and morphological dataset are that of Chatzimanolis \& Brunke (2019) with the addition of three morphological characters:

92. Mesothorax, elytra: (0) reduced, exposing tergum 2; (1) not reduced.

93. Hind wings: (0) absent; (1) present.

94. Abdomen, shape, lateral sides in dorsal view: (0) constricted anteriorly and expanded posteriorly; (1) more or less parallel-sided.

The taxon sample was that of Chatzimanolis \& Brunke (2019), with the addition of the three new taxa described in this paper. No molecular data were available for these new taxa. Phylogenetic analyses were conducted in MrBayes ver. 3.2.6 (Ronquist et al., 2012) (Bayesian) and IQ-TREE ver. 1.6 (Nguyen et al. 2015) (maximum likelihood, ML) with settings exactly as in Chatzimanolis \& Brunke (2019). Analyses in MrBayes were run on the CIPRES Science Gateway (phylo.org). Analyses were conducted on the total evidence dataset (4891 characters) of morphological (93 characters) and molecular data (4797 bp), which was initially partitioned into morphology and gene by codon position. Optimal partitioning scheme and model selection were determined using PartitionFinder2 (Lanfear et al. 2012), running on CIPRES with the settings used in Chatzimanolis \& Brunke (2019). Clade support for Bayesian and ML analyses was assessed using 1000 replicates of the ultrafast bootstrap (UFB) (Hoang et al. 2018) and an SH-aLRT test with 1000 replicates (Guindon et al., 2010). Nodes with Bayesian posterior probability (PP $>0.90$ ) were considered well supported, nodes with $\mathrm{PP}=0.80-0.89$ were considered to be weakly supported, and nodes with $\mathrm{PP}<0.80$ were considered unsupported. In the ML analysis, nodes with support values of both UFB $\geq 0.95$ and SH-aLRT $\geq 80$ were considered well supported, nodes with one of UFB $<95$ or SH-aLRT $<80$ were weakly supported, and nodes with both UFB $<95$ and SH-aLRT $<80$ were unsupported. Convergence of Bayesian analyses was assessed using Tracer ver. 1.6 (Rambaut et al. 2014) and by examining Potential Scale Reduction Factor (PSRF) and Average Standard Deviation of Split Frequency (ASDSF) values in the MrBayes output.

To test whether the three newly added characters were influencing the results of our analyses (perhaps due to convergence of morphological structures), a separate Bayesian and ML analysis (BA-mod, MLmod) was run without these three new characters. The morphological dataset, as well as the concatenated morphological and molecular datasets, are provided as supplemental materials (Supp. file 1, Supp. file 2).

\section{Results}

\section{Phylogenetic analyses}

For the molecular data, the partitioning scheme and corresponding models selected by PartitionFinder were exactly the same as Chatzimanolis \& Brunke (2019): (a) 28S, and positions 1+2 of ArgK, CO1, $\mathrm{CAD}, \mathrm{TP}$, and $\mathrm{Wg}-\mathrm{SYM}+\mathrm{I}+\mathrm{G}$; (b) position 3 of $\operatorname{ArgK}$, TP, CADA, CADC and $\mathrm{Wg}-\mathrm{GTR}+\mathrm{I}+\mathrm{G}$; (c) position of $\mathrm{CO} 1-\mathrm{HKY}+\mathrm{I}+\mathrm{G}$. Both Bayesian analyses converged after 50 million generations, with ASDSF values of 0.003 (all characters) and 0.004 (BA-mod) and nearly all PSRF values $=1.000$ (branch length of one clade 1.002 (all characters) or 1.004 (BA-mod). Effective sampling size of all analysis estimates was well over 200 .

Both Bayesian and ML analyses of the complete dataset (Fig. 1) recovered a monophyletic Ikaros gen. nov. with high support $(\mathrm{PP}=1$ (Bayesian) and SH-aLRT $=99, \mathrm{UFB}=100(\mathrm{ML})$ ). Within Ikaros gen. nov., I. polygonos gen. et sp. nov. was always resolved as the sister group to I. apteros gen. et sp. nov. + I. paramo gen. et sp. nov., though without support $(\mathrm{PP}=0.75$ and $\mathrm{SH}-\mathrm{aLRT}=78, \mathrm{UFB}=87)$. Topologies recovered in the BA-mod and ML-mod analyses were identical to their corresponding allcharacter analysis. Full topologies of all phylogenetic analyses are presented as supplementary figures 
(Supp. file 3). The overall tree topologies were largely congruent with that of Chatzimanolis \& Brunke (2019) and will not be discussed here.

While the monophyly and composition of Ikaros gen. nov. was consistent across analyses, the sister group of Ikaros gen. nov. differed between the Bayesian and ML analyses and could not be resolved with confidence (Fig. 1). The exclusion of morphological characters 92-94 did not impact these
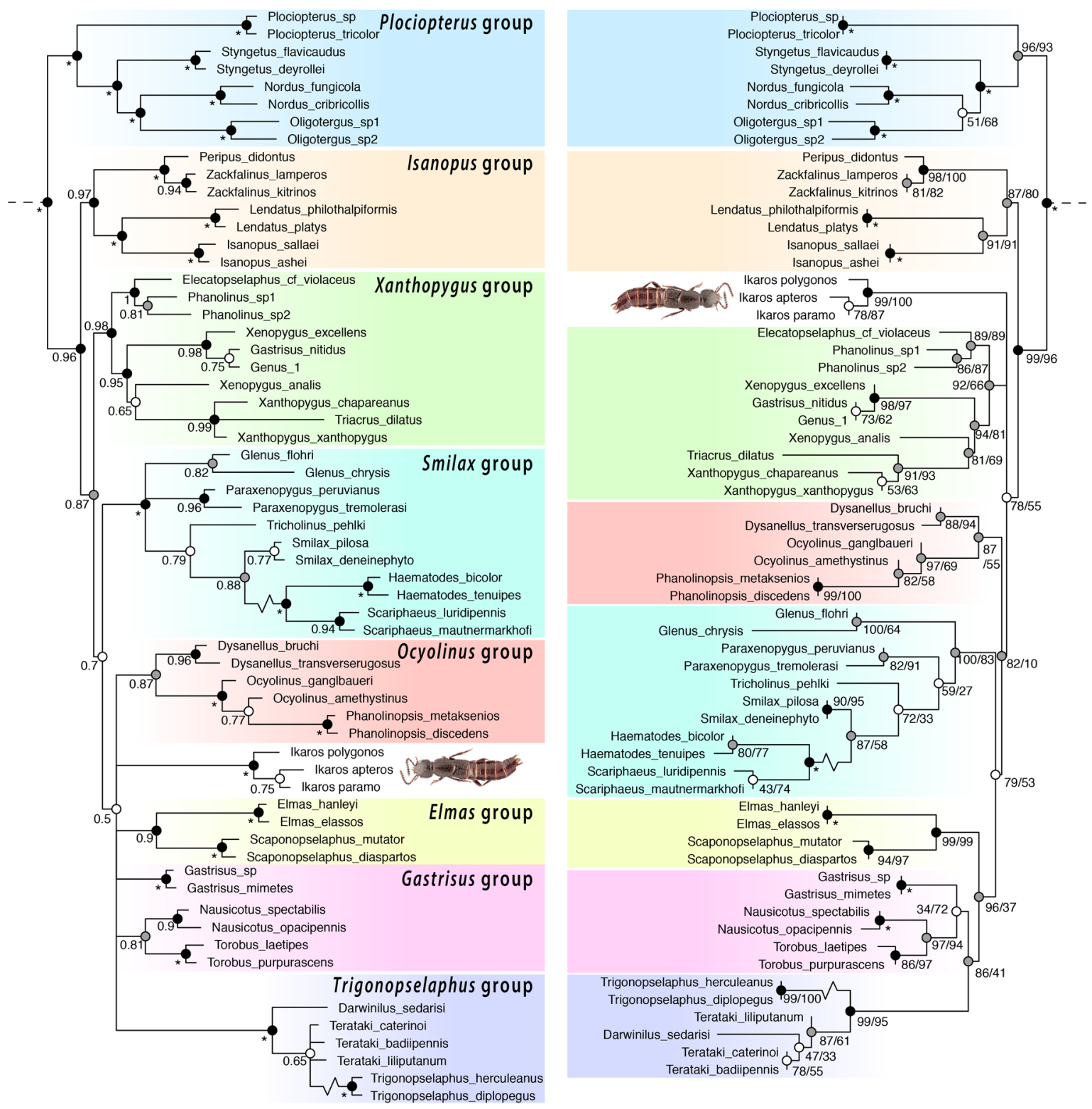

Fig. 1. Position of Ikaros gen. nov., based on partitioned, total evidence phylogenetic analyses of six genes and morphology (all characters), using Bayesian (left) and maximum likelihood (ML) (right), with outgroups removed for visualization. Posterior probabilities (Bayesian) are given to the left of the corresponding node, and SH-aLRT (left) and ultrafast bootstrap (UFB) (right) (ML) values are given to the right of the corresponding node. Nodes colored based on support: $\mathrm{PP} \geq 0.90$, UFB $\geq 95$ and SH-aLRT $\geq 80=$ black; PP $=0.80-0.89$, one of UFB $<95$ or SH-aLRT $<80=$ grey; $\mathrm{PP}<0.80$, both $\mathrm{UFB}<95$ and $\mathrm{SH}-\mathrm{aLRT}<80=$ white. 
relationships. In the Bayesian analyses, Ikaros gen. nov. was placed in an unsupported polytomy with the Trigonopselaphus, Ocyolinus, Elmas and Gastrisus groups. In the ML analyses, Ikaros gen. nov. was placed in an unsupported polytomy with the Xanthopygus group and a clade consisting of Trigonopselaphus, Gastrisus, Elmas, Ocyolinus, and Smilax groups.

\title{
Taxonomy
}

\author{
Class Insecta Linnaeus, 1758 \\ Order Coleoptera Linnaeus, 1758 \\ Superfamily Staphylinoidea Latreille, 1802 \\ Family Staphylinidae Latreille, 1802 \\ Subfamily Staphylininae Latreille, 1802 \\ Tribe Staphylinini Latreille, 1802 \\ Subtribe Xanthopygina Sharp, 1884 \\ Ikaros gen. nov. \\ urn:1sid:zoobank.org:act:547CE969-6222-48B6-BA7C-AAE86C5C4015
}

Figs $2-6$

\section{Type species}

Ikaros paramo gen. et sp. nov., here designated.

\section{Diagnosis}

Ikaros gen. nov. belongs in Xanthopygina based on the following two synapomorphies present: inferior marginal line of the pronotal hypomeron continues as a separate entity beyond anterior pronotal angles and curves around them, and hypostomal cavity moderately delimited (i.e., cavity surface without microsculpture or punctation different from the rest of nearby head surface). The genus can easily be distinguished from all other Xanthopygina based on the reduced elytra (exposing the $2^{\text {nd }}$ tergum), absence of hind wings and the shape of the abdomen: constricted anteriorly and expanded posteriorly.

\section{Etymology}

The word Ikaros is an alternate spelling of the word Icarus, the son of Daedalus who (in the Greek mythology) constructed the Labyrinth. Icarus and Daedalus escaped the Labyrinth by flying with wings made of feathers and glued by wax. However, Icarus flew too close to the sun and the wax melted. The name is rather appropriate for this genus considering these are species found in high altitudes that have lost their wings. The name is masculine.

\section{Description}

Habitus (Fig. 2). Body medium-sized, forebody 5.2-7.1 mm long, without long bristle-like setae.

Coloration. Brown to reddish-brown.

HEAD. Shape rectangular; head length in comparison to pronotum shorter to subequal. Eye size small, less than $1 / 2$ length of head. Postclypeus, in comparison to frons, not deflexed; anterior margin slightly emarginate. Middle of epicranium impunctate but with microsculpture. Postmandibular ridge laterally; with deep punctures demarcating raised postmandibular ridge dorsolaterally absent. Gular sutures not joined before neck, extended close to each other at base of head capsule. Nuchal ridge incomplete dorsally. Neck disc with dense, moderately coarse punctures. Antennae with relative width of antennomere 1 same width or slightly wider than antennomere 2 . Antennomeres 1-5 longer than wide; 5-10 subquadrate. Antennomere 3, 2.5 times as long as wide or less; antennomere 4 with tomentose 
pubescence; antennomeres 4-10 cylindrical in shape; antennomeres 5-10 without club; antennomeres 8-10 symmetrical, quadrate to elongate; antennomere 6 with curved, distinctly longer and thicker subapical setae than other macrosetae, forming circlet; antennomere 11 in males slightly longer than 10 . Mouthparts with labrum having broadly U-shaped emargination, lobes strongly separated. Mandibles with relative length typical (i.e., closed mandible not extending beyond lateral margin of head); without asymmetrical torsion. Mandible in dorsal view curved from apical half; in lateral aspect: straight; left and right mandible each with one tooth. Maxilla with galea much shorter than palpus; maxillary palpus with palpomere 3 distinctly shorter than palpomere 2; palpomere 4 distinctly longer than palpomere 3 ; palpomere 4 not dilated. Labial palpus with palpomere 3 widest apically, subparallel-sided (widest before apex in I. polygonos gen. et sp. nov.); palpomere 3 without long dense setae on entire lateral sides. Ligula small, entire. Mentum with alpha seta present; hypostomal cavity present; moderately delimited.

Pronotum. With shape of lateral margins in dorsal view posteriad of midpoint straight to sinuate; anterior angles in dorsal view not strongly acuminate and produced laterad. Pronotum near anterolateral angles without raised impunctate spots; anterolateral corners with punctation; disc of pronotum with punctation beyond midlength (but punctation not continuing beyond midlength in I. apteros gen. et sp. nov.); punctation varies but microsculpture present; without coarse punctures impressed in flange at posterior angle of pronotum. Hypomeron with superior marginal line continuous to anterior margin; superior marginal line without distinct deflection under anterior angles in ventral view; inferior marginal line of hypomeron continued as a separate entity beyond anterior pronotal angles and curving around them. Postcoxal process absent. Basisternum slightly longer than furcasternum; basisternum with pair of macrosetae, situated far from anterior margin of prosternum.

ELYTRA. Reduced, exposing tergum 2. Hind wings absent. Elytra setae not reduced, easily seen at low magnification; without patches of white setae. Elytra without contiguous polygon-shaped meshed microsculpture. Mesoscutellum with dense cluster of punctures medially. Mesoventrite without median carina; mesoventral process broadly triangular; process extended distally to distance $2 / 5$ between mesocoxae. Metaventrite with small punctures; metaventral process small, rounded, triangular extended to beginning of metacoxae.

LEGS. With tarsal segmentation 5-5-5; profemora without lateroventral apical spines; protarsi with modified pale (adhesive) setae ventrally; tarsomeres 1-4 of protarsi dorsoventrally flattened. Mesocoxae moderately separated, intercoxal area distinctly recessed compared to mesoventrital process only. Metacoxae without coxal shield; metatibia without thick and long apical spurs but smaller spurs (and spines) present; tarsomeres 3-5 of metatarsi with chaetotaxy, developed only at margins of dorsal surface; dorsal surface of tarsomeres glabrous along midline. Pretarsal claws with empodial setae.

AвDOMEN. With lateral sides in dorsal view constricted anteriorly and expanded posteriorly; with protergal glands having well-developed acetabula. Anterior basal transverse carina on terga 3 and 4 without pair of accessory ridges; tergum 3 without posterior basal transverse carina or curved (arched-like) on disc (except arched-like carina present on I. polygonos gen. et sp. nov. on terga 3-5). Tergum 5 without pair of accessory ridges on anterior basal transverse carina; centre of tergum 5 punctate; posterior half of tergum 5 in lateral view not appearing bulging. Sternum 3 with straight to arcuate basal transverse carina medially; basal transverse carina laterally not sinuate. Sternum 4 without basal transverse carina medially. Sternum 5 with dense, meshed microsculpture anterolaterally, appearing different in texture to posterior portion. Sternum 7 with sparse (punctures separated by more than two puncture width) punctation laterally.

MALE Genitalia. With secondary sexual structures (medial emargination) on sterna 7 and 8; without porose structure on sternum 7. Aedeagus as in Figs 3-5; with long median lobe and single paramere; 
paramere with sensory peg setae; median lobe with single subapical tooth; without apical tooth, carina or paired apex.

Female Genitalia. Without secondary sexual structures. Spermathecae not sclerotized.

\section{Habitat}

Ikaros paramo gen. et sp. nov. was collected in dry to sub-humid paramo, an ecosystem characterized as high altitude, tropical, montane, and above the tree line. Ikaros polygonos gen. et sp. nov. was collected from an area with interspersed páramo and shrubby/treed patches (R. Anderson pers. com.), and judging from the locality and elevation, Ikaros apteros gen. et sp. nov. appears to live in a similar habitat.
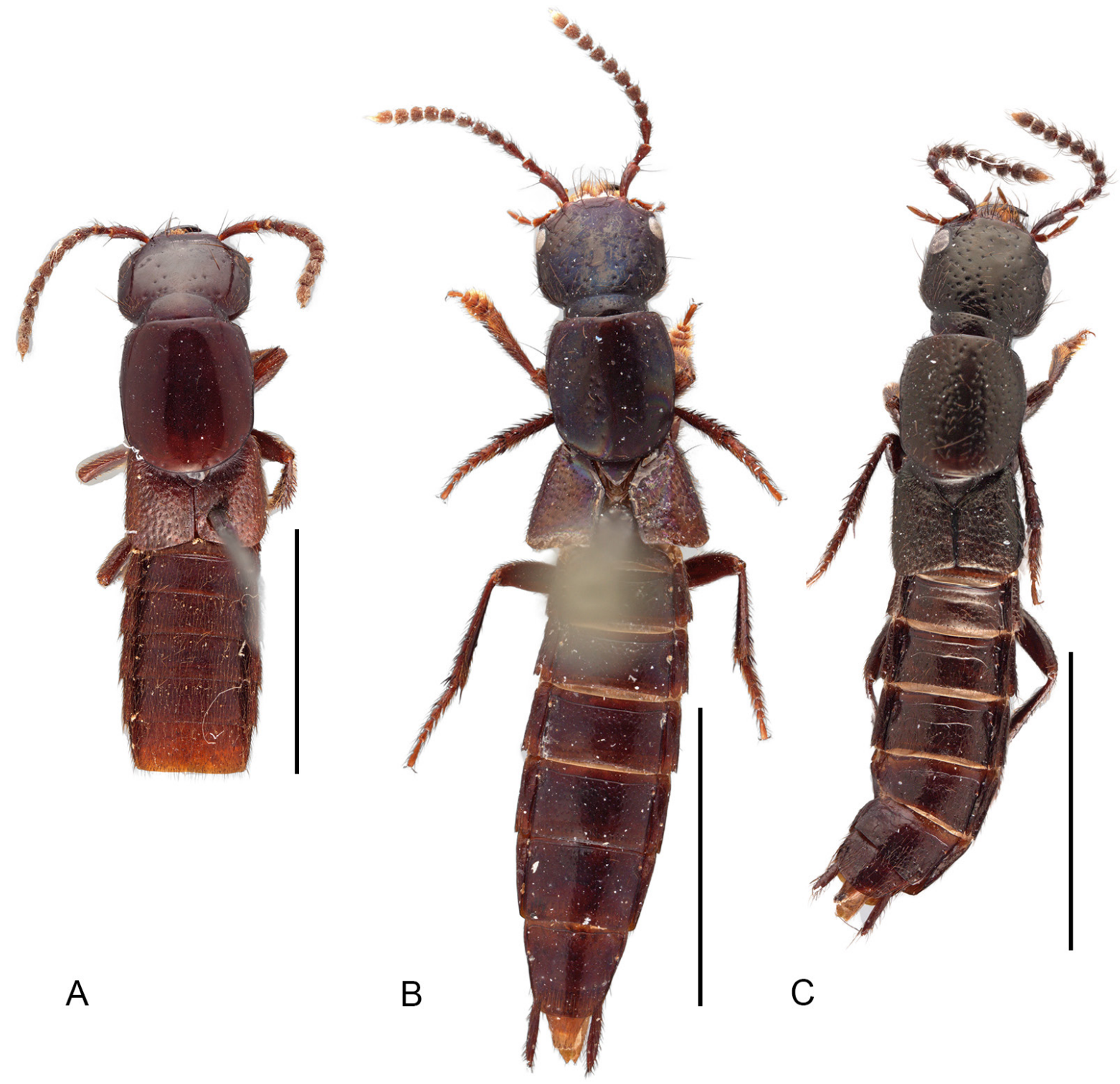

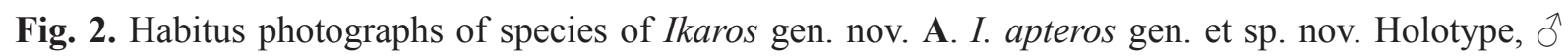
(SDEI). B. I. paramo gen. et sp. nov. Paratype, ô (barcode: SM05500251, UTCI). C. I. polygonos gen. et sp. nov. Holotype, $\widehat{O}^{\lambda}$ (barcode: SM0114364, MIZA). Scale bars $=5 \mathrm{~mm}$. 
Ikaros apteros gen. et sp. nov.

urn:Isid:zoobank.org:act:2FB02118-DAD8-4812-AFFE-2ADA3356F97B

Figs $2 \mathrm{~A}, 3$

\section{Diagnosis}

Among species of Ikaros gen. nov. that lack arch-like carina on terga 3-5, I. apteros gen. et sp. nov. lacks any punctures on the pronotum, beyond the punctures along the median area, whereas I. paramo gen. et sp. nov. has punctures arranged in multiple rows.

\section{Etymology}

The specific epithet is derived from the Greek word ' $\alpha$ $\pi \tau \varepsilon \rho \varsigma^{\prime}$ ' ('without wings') and refers to the lack of hind wings. It is treated here as a noun in apposition.

\section{Type material}

Holotype (here designated)

COUNTRY UNKNOWN - O; "Nov. Gran. [Nova Granada], L.F.S / coll. Kraatz / Xanthopygina ref. Xanthopygus det. A. Brunke 2012 / HOLOTYPE Ikaros apteros Chatzimanolis and Brunke, des. Chatzimanolis and Brunke 2020"; SDEI.

\section{Paratype}

COLOMBIA • O; ; “Colombia, Cundinamarca, PNN Chingaza Charrascalles, 431' N 7345’ W, 2990 m, Winkler, 19-21.vi.2002, F. Guzmán Leg., M3239 / SM0548722 [barcode label] / PARATYPE Ikaros apteros Chatzimanolis and Brunke, des. Chatzimanolis and Brunke 2020"; SEMC.

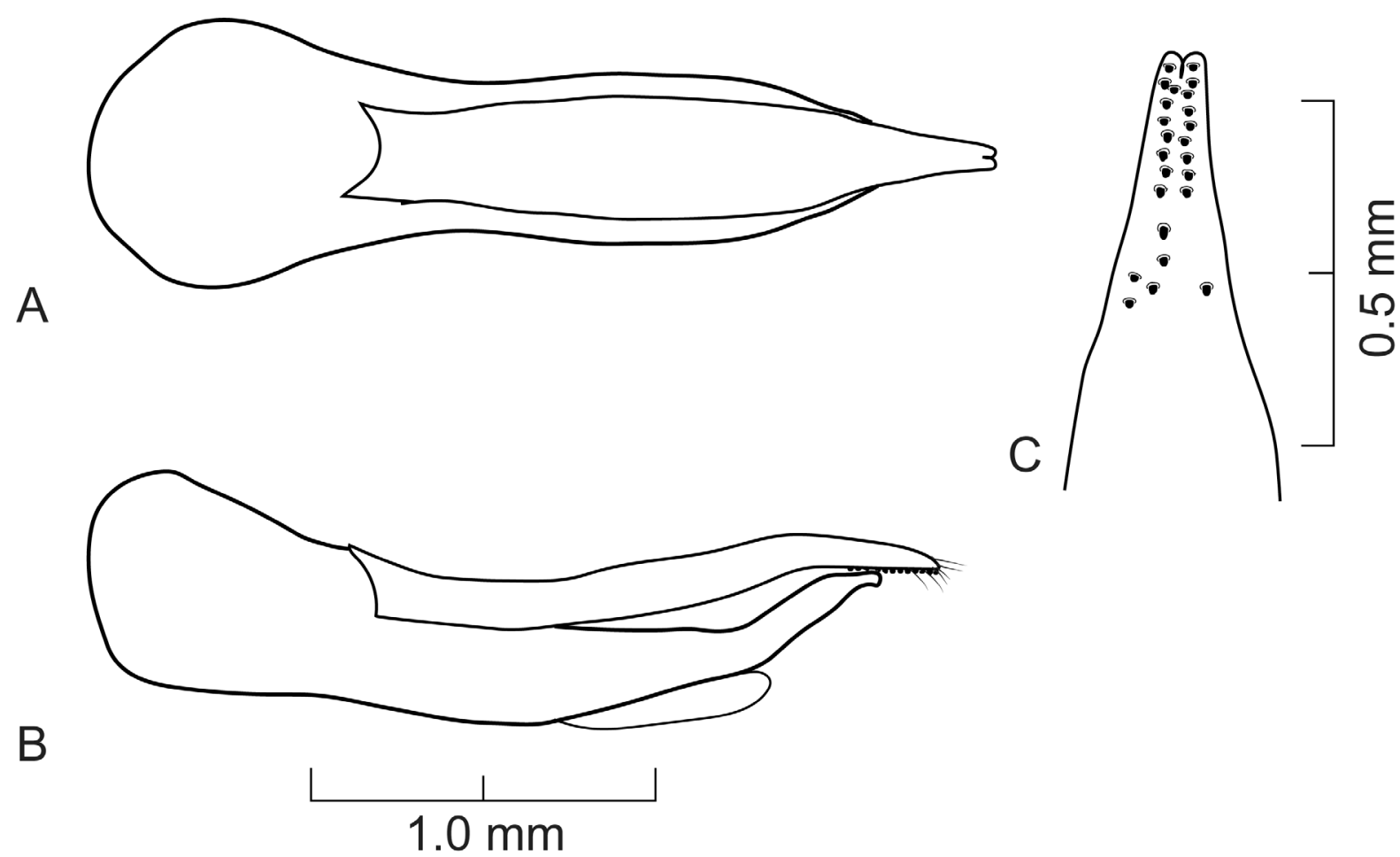

Fig. 3. Aedeagus of Ikaros apteros gen. et sp. nov. A. Dorsal view. B. Lateral view. C. Detail of paramere, ventral view. 


\section{Description}

Forebody length $7.1 \mathrm{~mm}$ long. Coloration reddish brown with head and mouthparts slightly darker brown. Head transverse, $\mathrm{HW} / \mathrm{HL}$ ratio $=1.18$. Epicranium mostly impunctate, with few large punctures posteriorly, medially and around margin of head and eye; with faint polygon-shaped microsculpture. Labial palpus with palpomere 3 widest apically, subparallel-sided. Antennomeres with crown-like macrosetae shorter than length of antennomere. Pronotum longer than wide, PW/PL ratio $=0.91$; surface of pronotum impunctate except two punctures on each side of median area and few punctures around margin; with faint polygon-shaped microsculpture. Elytra shorter than pronotum, EL/PL ratio $=0.75$. Elytra with large, deep contiguous punctures and dense polygon-shaped microsculpture. Abdominal terga 3-5 without arch-like carina. Male secondary sexual structures with shallow but broad emargination on sternum 7; with deep, broad V-shaped emargination on sternum 8; borders of emargination on sternum 7 and 8 appearing 'shaved' (with no setae). Aedeagus as in Fig. 3; in dorsal view paramere longer than median lobe; converging to elongate, narrow tip; apex of paramere with small emargination; in lateral view paramere concave, becoming narrower. Median lobe in dorsal view narrowing to rounded apex; in lateral view median lobe becoming narrower near flattened apex, with no subapical tooth.

\section{Distribution}

Known from the National Park Chingaza in the department of Cundinamarca, Colombia (Fig. 6). The holotype was collected in the Republic of New Granada (1831-1858), which refers to a region that included primarily Colombia and Panama, and smaller areas from the countries of Brazil, Costa Rica, Ecuador, Peru and Venezuela.

Ikaros paramo gen. et sp. nov. urn:1sid:zoobank.org:act:8FE14A94-3312-4BA8-901A-DAE9542DF2B4

Figs 2B, 4

\section{Diagnosis}

Among species of Ikaros gen. nov. that lack arch-like carina on terga 3-5, I. paramo gen. et sp. nov. has punctures arranged in multiple rows, whereas I. apteros gen. et sp. nov. lacks any punctures on the pronotum, beyond the punctures along the median area.

\section{Etymology}

The specific epithet is derived from the name of the ecosystem (páramo) where the specimens were collected. It is treated here as a noun in apposition.

\section{Type material}

Holotype (here designated)

COLOMBIA - ^’; “Colombia: Boyacá, SFF Iguaque Qda. Los Francos, $5^{\circ} 25^{\prime} \mathrm{N} 73^{\circ} 27^{\prime} \mathrm{W}, 2860 \mathrm{~m}$, Pitfall, 9-13.iii.2001, P. Reina Leg., M.1345 / SM0650483 [barcode label] / HOLOTYPE Ikaros paramo Chatzimanolis and Brunke, des. Chatzimanolis and Brunke 2020"; IAVH.

\section{Paratypes}

COLOMBIA - 1 \} \text { ; “Colombia: Boyacá, SFF Iguaque Qda. Los Francos, } 5 ^ { \circ } 2 5 ^ { \prime } \mathrm { N } 7 3 ^ { \circ } 2 7 ^ { \prime } \mathrm { W } , 2 8 5 0 \mathrm { m } \text { , } Pitfall, 3-5.ix.2000, P. Reina Leg., M.756 / SM05500251 [barcode label]"; UTCI • 1 đે; same collection data as for preceding; "SM05500250 [barcode label]"; SEMC • 1 q; "Colombia: Boyacá, SFF Iguaque Cabanā Mamaramos, m4, 52 $5^{\prime} \mathrm{N} 73^{\circ} 27^{\prime} \mathrm{W}, 2855$ m, Malaise, 19.iv-6.v.2000, P. Reina Leg., M.55 / SM0548719 [barcode label]; SEMC • 1 क ; “Colombia: Boyacá, SFF Iguaque Cabanā Carrizal, $5^{\circ} 25^{\prime} \mathrm{N}$ 73²7’W, 2850 m, Pitfall, 9-13.iii.2001, P. Reina Leg., M.1346 / SM0645316 [barcode label]”; SEMC. 
All paratypes with label "PARATYPE Ikaros paramo Chatzimanolis and Brunke, des. Chatzimanolis and Brunke 2020".

\section{Description}

Forebody length 5.3-5.9 mm long. Coloration reddish brown with head and mouthparts slightly darker brown. Head transverse, HW/HL ratio $=1.21$. Epicranium with numerous large punctures, except impunctate centre; punctures not contiguous, distance between punctures varies; with faint polygonshaped microsculpture. Labial palpus with palpomere 3 widest apically, subparallel-sided. Antennomeres with crown-like macrosetae shorter than length of antennomere. Pronotum longer than wide, PW/PL ratio $=0.88$; surface of pronotum with a median impunctate area as wide as 4-5 punctures; with 2-3 rows of disorganized punctures in addition to rows flanking impunctate centre; with faint polygonshaped microsculpture. Elytra shorter than pronotum, EL/PL ratio $=0.79$. Elytra with large, deep punctures, distance between punctures equals to width of 0.5-1 punctures; elytra with faint polygonshaped microsculpture. Abdominal terga 3-5 without arch-like carina. Male secondary sexual structures with shallow emargination on sternum 7; with shallow, narrow U-shaped emargination on sternum 8; borders of emargination on sternum 7 and 8 appearing 'shaved' (with no setae), but less so than in I. apteros gen. et sp. nov. Aedeagus as in Fig. 4; in dorsal view paramere subequal to median lobe; paramere broad, converging to rounded tip; in lateral view paramere more or less straight. Median lobe in dorsal view broad, narrowing to rounded apex; in lateral view median lobe becoming narrower near apex, with small subapical tooth.

\section{Distribution}

This species is only known from Iguaque Fauna and Flora Sanctuary (SFF Iguaque) in the Boyacá Department of Colombia (Fig. 6).
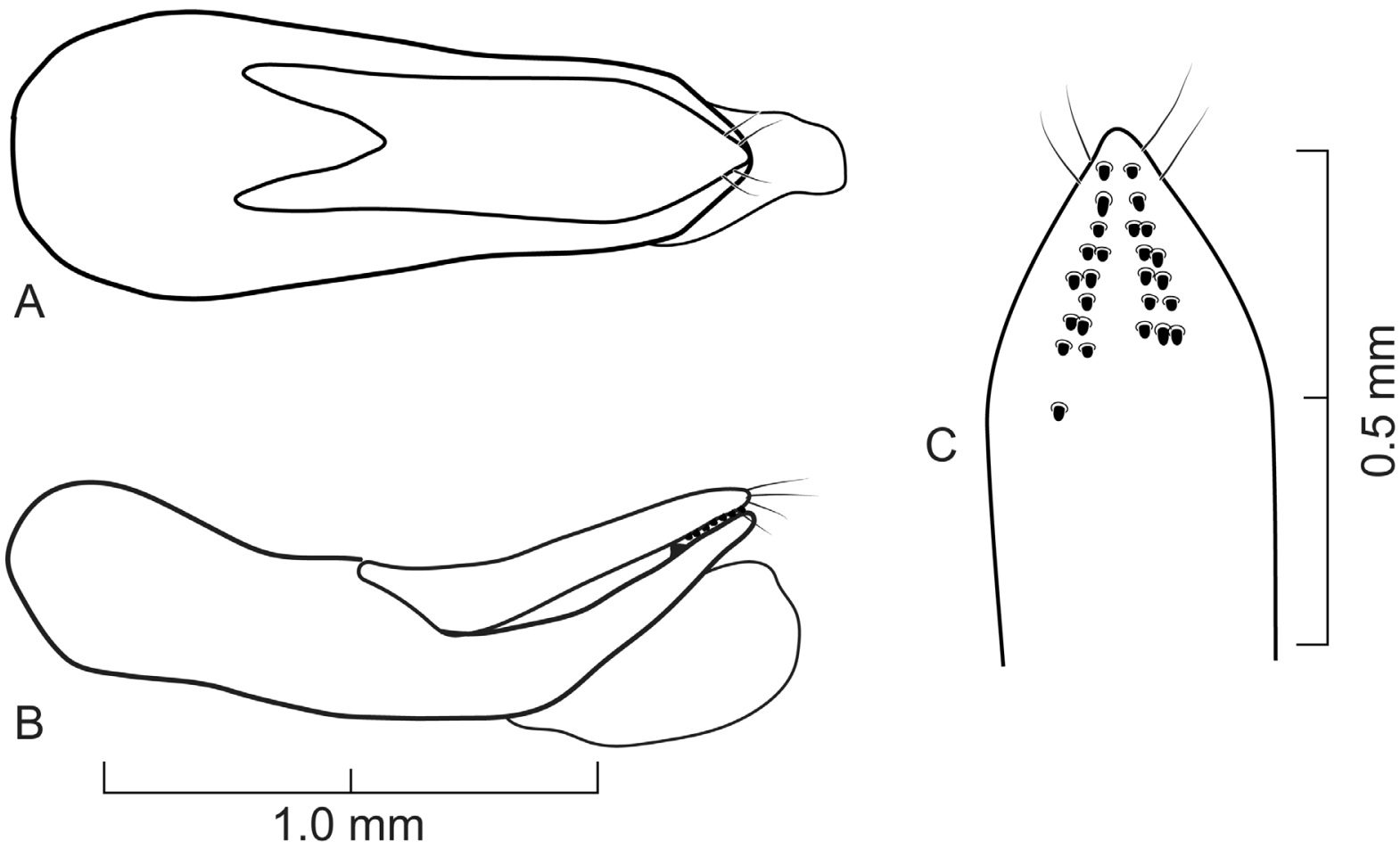

Fig. 4. Aedeagus of Ikaros paramo gen. et sp. nov. A. Dorsal view. B. Lateral view. C. Detail of paramere, ventral view. 


\section{Remarks}

The holotype is currently in the collection of SEMC but due to the collecting permit requirements (Z. Falin pers. com.), it will be transferred to the IAVH collection in the near future.

Ikaros polygonos gen. et sp. nov.

urn:1sid:zoobank.org:act:D7581C8A-2D3A-4D1A-977B-F82E03BD07A7

Figs $2 \mathrm{C}, 5$

\section{Diagnosis}

Ikaros polygonos gen. et sp. nov. can be distinguished from other species in this genus by the presence of an arch-like carina on terga 3-5 (absent in the other two species); the stark polygon-shaped microsculpture on the dorsal surface of the head, thorax and elytra (absent in the other two species) and the long crownlike macrosetae (macrosetae at least twice as long as antennomeres) on the antennomeres (macrosetae much smaller in the other two species).

\section{Etymology}

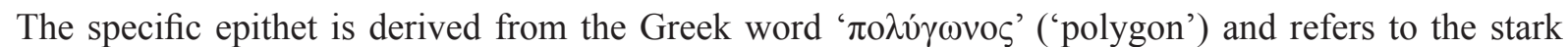
polygon-shaped microsculpture of the head, thorax and elytra. It is treated here as a noun in apposition.

\section{Type material}

Holotype (here designated)

VENEZUELA • đ; "Venezuela, Merida, Tabay, 7 km E. La Mucuy Station, Sierra Nevada Natl. Park, 2300-2700 m, 8³7'44"N 71²'26"W, 24.v.1998, R. Anderson, VEN1A98 036B. ex: upper montane

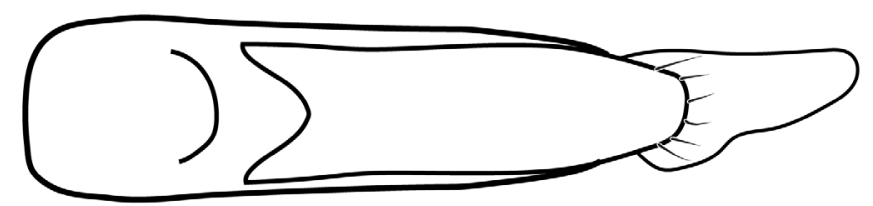

\section{A}
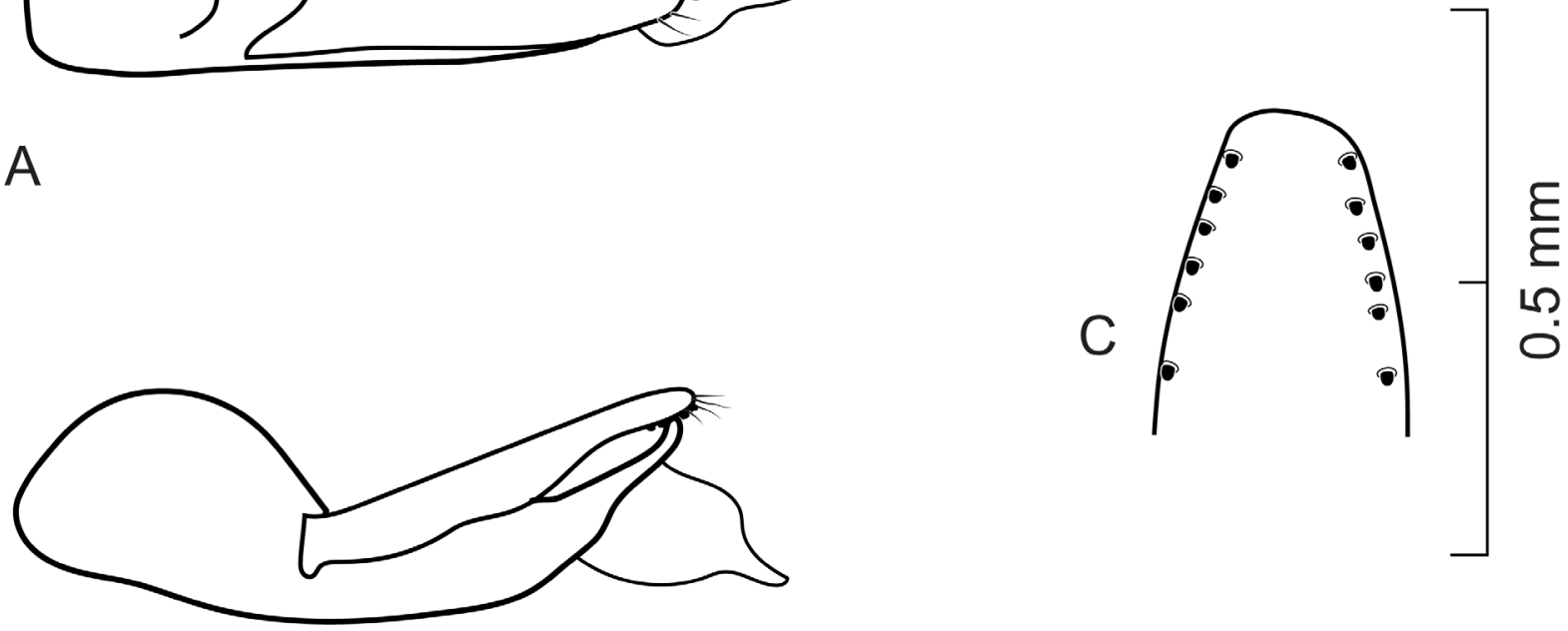

B

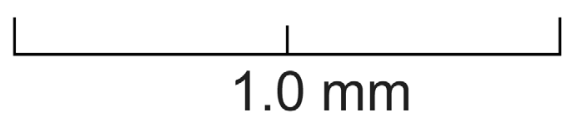

Fig. 5. Aedeagus of Ikaros polygonos gen. et sp. nov. A. Dorsal view. B. Lateral view. C. Detail of paramere, ventral view. 
forest litter / SM0114364 [barcode label] / HOLOTYPE Ikaros polygonos Chatzimanolis and Brunke, des. Chatzimanolis and Brunke 2020"; MIZA.

\section{Description}

Forebody length $5.2 \mathrm{~mm}$ long. Coloration of body reddish brown, with head and pronotum having undertones of metallic green-brown. Head transverse, $\mathrm{HW} / \mathrm{HL}$ ratio $=1.16$. Epicranium with numerous large punctures, except impunctate centre; punctures not contiguous, distance between punctures typically width of 1-2 punctures; with stark polygon-shaped microsculpture. Labial palpus with palpomere 3 widest before apex. Antennomeres with crown-like macrosetae at least twice as long as antennomeres. Pronotum longer than wide, $\mathrm{PW} / \mathrm{PL}$ ratio $=0.9$; surface of pronotum with a median impunctate area as wide as 2-3 punctures; with 4-5 rows of punctures in addition to rows flanking impunctate centre; with stark polygon-shaped microsculpture. Elytra shorter than pronotum, EL/PL ratio $=0.8$. Elytra with large, deep contiguous punctures and dense polygon-shaped microsculpture. Abdominal terga 3-5 with archlike carina. Male secondary sexual structures with shallow emargination on sternum 7; with shadow, small U-shaped emargination on sternum 8; borders of emargination on sternum 7 and 8 appearing 'shaved' (with no setae), but less so than in I. apteros gen. et sp. nov. Aedeagus as in Fig. 5; in dorsal view paramere slightly longer than median lobe; paramere broad, converging to broad, rounded tip; in lateral view paramere narrower apically. Median lobe in dorsal view becoming narrow to small apex; in lateral view median lobe concave, becoming narrower near curved apex, without subapical tooth.

\section{Distribution}

Known only from the type locality in Sierra Nevada National Park in Venezuela (Fig. 6).

\section{Remarks}

The holotype is currently in the collection of SEMC but due to the collecting permit requirements (R. Anderson pers. com.), it will be transferred to the MIZA collection in the near future.

\section{Key to the species of Ikaros gen. nov.}

1. Arch-like carina present on terga 3-5; stark polygon-shaped microsculpture present on the dorsal surface of the head and thorax; long (macrosetae at least twice as long as antennomeres) crown-like macrosetae on antennomeres

I. polygonos gen. et sp. nov.

- Arch-like carina absent on terga 3-5; without stark polygon-shaped microsculpture on the dorsal surface of the head and thorax; crown-like macrosetae on antennomeres not as long, shorter than antennomeres

2. Disc of pronotum with only the few punctures of the dorsal row

I. apteros gen. et sp. nov.

- Disc of pronotum with multiple rows of punctures I. paramo gen. et sp. nov.

\section{Discussion}

Until recently, there was no comprehensive phylogeny of the subtribe, but Chatzimanolis \& Brunke (2019) using molecular and morphological data placed all existing genera of the subtribe into a phylogenetic context and established eight groups of genera: the Plociopterus, Isanopus, Xanthopygus, Smilax, Elmas, Gastrisus, Ocyolinus and Trigonopselaphus groups. The phylogeny presented in this paper is largely congruent with that of Chatzimanolis \& Brunke (2019). The major difference is in the composition of the Gastrisus group of genera. In the Bayesian analyses, the addition of the genus Ikaros gen. nov. to the dataset splits the Gastrisus group into two subgroups (one composed of taxa in the genus Gastrisus Sharp, 1876 and the other composed of species in the genera Nausicotus Sharp, 1884 and Torobus) and renders them in a polytomy along with the Elmas, Ocyolinus and Trigonopselaphus 
groups and Ikaros gen. nov. It is possible that additional molecular or morphological data may unite the taxa of the Gastrisus group with the species of Ikaros gen. nov. as a clade, although the exact placement of Ikaros gen. nov. among the various groups cannot be conclusively determined given our data.

The three new species described here formed a clade regardless of the analyses method (Bayesian or maximum likelihood) or whether the three new morphological characters were included or excluded. Initially, we had hypothesized that the three species presented here may not be closely related, and their similarities may be due to convergence associated with aptery. One morphological feature that caused suspicion of monophyly was the presence of the arch-like carina on terga 3-5 in I. polygonos gen. et

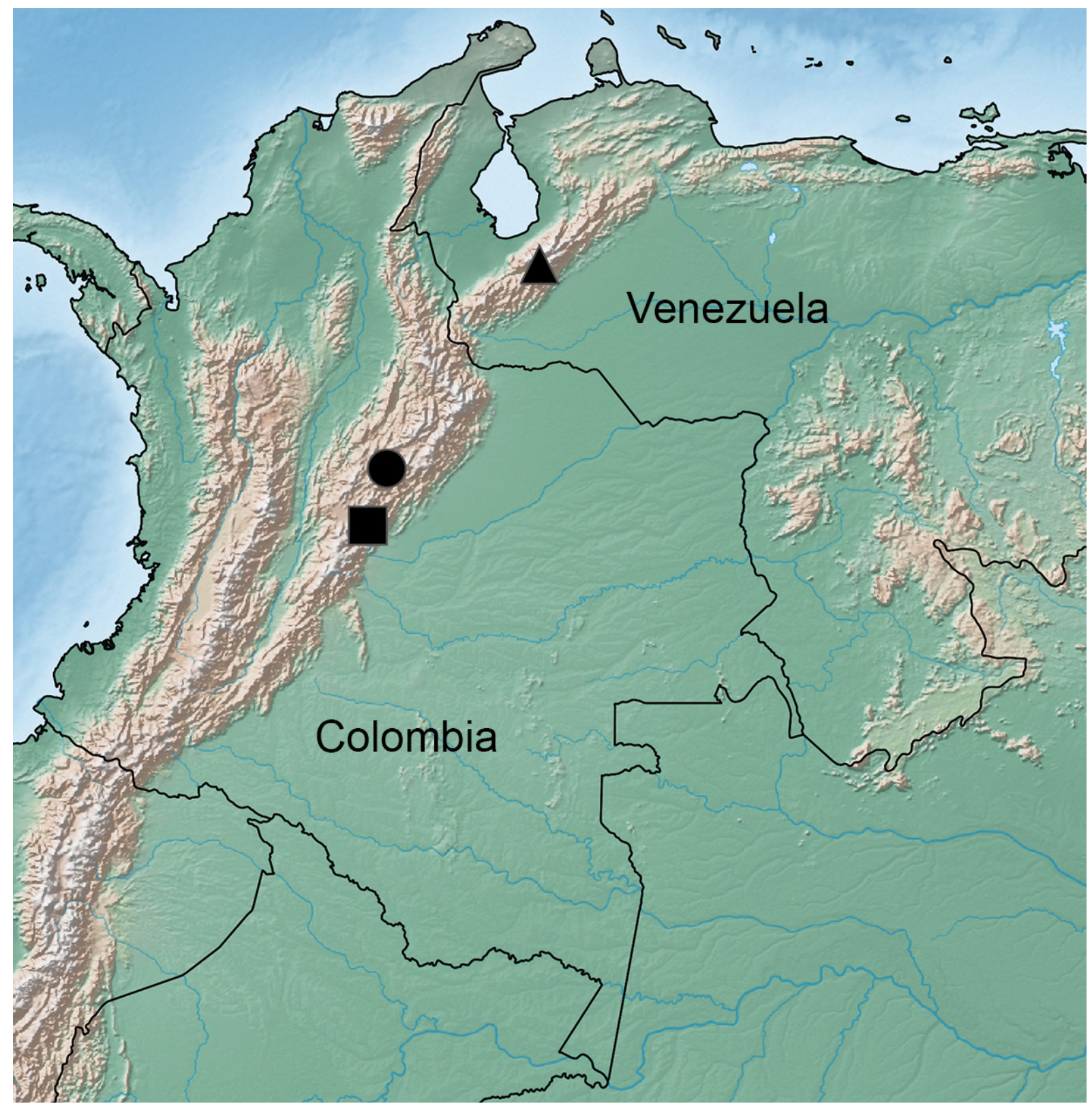

Fig. 6. Distribution map of Ikaros apteros gen. et sp. nov. (square), I. paramo gen. et sp. nov. (circle) and I. polygonos gen. et sp. nov. (triangle). 
sp. nov., which is absent in the other two species. However, our analyses do not support this hypothesis and perhaps further molecular data can clarify this situation.

The most likely reason for the loss of hind wings observed in Ikaros gen. nov. is their high-altitude habitat in the Northern Andes. Loss of hind wings is common in rove beetles found in high elevations (e.g., in Atheta Thomson, 1858: Assing 2004; Dasycerus Brongniart, 1800: Wheeler \& McHugh 1994; Lathrobium Gravenhorst, 1802: Peng et al. 2013). The switch from bright metallic coloration to dull brown is harder to explain but it might also be due to the high-altitude habitat. Although some other Xanthopygina lack bright coloration (e.g., species in Gastrisus, Oligotergus Bierig, 1937 and Xanthopygus Kraatz, 1857), most Xanthopygina are presumed to be predators (Chatzimanolis 2003), and deciphering the role of coloration here will probably require direct observations of the natural history of Ikaros gen. nov.

\section{Acknowledgments}

We thank R. Anderson and A. Solodovnikov and two anonymous reviewers for comments, and Zack Falin and Stephan Blank for the loan of specimens. Financial support was provided by an RCA grant to SC from the College of Arts and Sciences, University of Tennessee at Chattanooga, and A-base funding to $\mathrm{AB}$ from Agriculture and Agri-Food Canada project J-002276.

\section{References}

Assing V. 2004. A new microphthalmous Atheta species from Yunnan, China (Coleoptera: Staphylinidae, Aleocharinae). Linzer biologische Beiträge 36 (2): 589-582.

Bordoni A. 2020. New data on the Afrotropical Xantholinini. 10. New species of Notolinopsis collected by Jiři Janák and Petr Bulirsch in South Africa (Coleoptera: Staphylinidae). Studies and Reports, Taxonomical Series 16 (1): 7-12.

Brunke A.J. \& Chatzimanolis S. 2018. A revision of Haematodes Laporte and Weiserianum Bernhauer (Coleoptera: Staphylinidae: Staphylininae: Xanthopygina). PeerJ 6: e4582.

https://doi.org/10.7717/peerj.4582

Chatzimanolis S. 2003. Natural history and behavior of Nordus fungicola (Coleoptera: Staphylinidae). Annals of the Entomological Society of America 96 (3): 225-230. https://doi.org/10.1603/0013-8746(2003)096[0225:NHABON]2.0.CO;2

Chatzimanolis S. 2014. Phylogeny of xanthopygine rove beetles based on six molecular loci. Systematic Entomology 39 (1): 141-149. https://doi.org/10.1111/syen.12040

Chatzimanolis S. 2017. And then there were six: a revision of the genus Phanolinopsis Scheerpeltz (Coleoptera: Staphylinidae: Staphylininae). Zootaxa 4323 (1): 49-67.

https://doi.org/10.11646/zootaxa.4323.1.4

Chatzimanolis S.2018. A review of the genera Dysanellus Bernhauer and Torobus Herman (Staphylinidae: Staphylininae: Staphylinini). The Coleopterists Bulletin 72 (2): 279-291. https://doi.org/10.1649/0010-065X-72.2.279

Chatzimanolis S. 2019. Lendatus, a new genus of Xanthopygina (Coleoptera: Staphylinidae: Staphylininae) with description of three new species. PeerJ 7: e7947.

https://doi.org/10.7717/peerj. 7947

Chatzimanolis S. 2020. On the identify of Gastrisus modestus (Bernhauer), with an updated diagnosis and a key for Dysanellus Bernhauer (Staphylinidae: Staphylininae: Staphylinini). The Coleopterists Bulletin 74 (3): 598-600. https://doi.org/10.1649/0010-065X-74.3.598 
Chatzimanolis S. \& Brunke A.J. 2019. A phylogeny of Xanthopygina (Insecta, Coleoptera) reveals major lineages and the origin of myrmecophily. Zoologica Scripta 48 (4): 494-506.

https://doi.org/10.1111/zsc. 12358

Chatzimanolis S. \& Hightower H.J. 2019. Peripus, a new genus of Xanthopygina (Coleoptera: Staphylinidae) from South America. Zootaxa 4648 (2): 371-383.

https://doi.org/10.11646/zootaxa.4648.2.10

Clarke D.J. 2018. Systematics, natural history, and evolution of the saw-lipped rove beetles (Euaesthetinae): progress and prospects for future research. In: Betz O., Ulrich I. \& Klimaszewski J. (eds) Biology of Rove Beetles (Staphylinidae): 81-114. Springer, Cham.

Guindon S., Dufayard J.-F., Lefort V., Anisimova M., Hordijk W. \& Gascuel O. 2010. New algorithms and methods to estimate maximum-likelihood phylogenies: assessing the performance of PhyML 3.0. Systematic Biology 59 (3): 307-321. https://doi.org/10.1093/sysbio/syq010

Hoang D.T., Chernomor O., von Haeseler A., Minh B.Q. \& Vinh L.S. 2018. UFBoot2: Improving the ultrafast bootstrap approximation. Molecular Biology and Evolution 35 (2): 518-522.

https://doi.org/10.1093/molbev/msx281

Lanfear R., Calcott B., Ho S. \& Guindon S. 2012. PartitionFinder: combined selection of partitioning schemes and substitution models for phylogenetic analyses. Molecular Biology and Evolution 29 (6): 1695-1701. https://doi.org/10.1093/molbev/mss020

Nguyen L.-T., Schmidt H.A., von Haeseler A. \& Minh B.Q. 2015. IQ-TREE: a fast and effective stochastic algorithm for estimating maximum likelihood phylogenies. Molecular Biology and Evolution 32 (1): 268-274. https://doi.org/10.1093/molbev/msu300

Peng Z., Li L.Z. \& Zhao M.J. 2013. Eight new apterous Lathrobium species (Coleoptera, Staphylinidae) from Sichuan, Southwest China. ZooKeys 303: 1-21. https://doi.org/10.3897/zookeys.303.5328

Puthz V. 2015. Three new apterous Stenus species from the high mountains of Mexico and Guatemala (Coleoptera: Staphylinidae). Dugesiana 22 (2): 111-114.

Rambaut A., Suchard M., Xie D. \& Drummond A. 2014. Tracer v1.6.

Available from http://tree.bio.ed.ac.uk/software/tracer/ [accessed 19 Mar. 2021].

Ronquist F., Teslenko M., van der Mark P., Ayres D., Darling A., Höhna S., Larget B., Liu L., Suchard M. \& Huelsenbeck J. 2012. MrBayes 3.2: efficient Bayesian phylogenetic inference and model choice across a large model space. Systematic Biology 61 (3): 539-542. https://doi.org/10.1093/sysbio/sys029

Saito K., Yamamoto D., Maruyama M. \& Okabe Y. 2014. Asymmetric hindwing foldings in rove beetles. Proceedings of the National Academy of Sciences of the Unites States of America 111 (46): 16349-16352. https://doi.org/10.1073/pnas.1409468111

Schomann A. \& Solodovnikov A. 2016. Phylogenetic placement of the austral rove beetle genus Hyperomma triggers changes in classification of Paederinae (Coleoptera: Staphylinidae). Zoologica Scripta 46 (3): 336-347. https://doi.org/10.1111/zsc.12209

Shorthouse D.P. 2010. SimpleMappr, an online tool to produce publication-quality point maps. Available from http://www.simplemappr.net [accessed 18 Oct. 2020].

Smetana A. 1995. Rove beetles of the subtribe Philonthina of America North of Mexico (Coleoptera: Staphylinidae) classification, phylogeny and taxonomic revision. Memoirs on Entomology, International, Volume 3. Associated Press, Gainesville. 
Wheeler Q.D. \& McHugh J.V. 1994. A new southern Appalachian species, Dasycerus bicolor (Coleoptera: Staphylinidae: Dasycerinae) from declining endemic fir forests. The Coleopterists Bulletin 48 (3): 265-271. https://www.jstor.org/stable/4009111

Wheeler Q.D. \& Platnick N.I. 2000. The phylogenetic species concept (sensu Wheeler and Platnick). In: Wheeler Q.D. \& Meier R. (eds) Species Concepts and Phylogenetic Theory: A Debate: 55-69. Columbia University Press, New York.

Żyła D. \& Solodovnikov A. 2020. Multilocus phylogeny defines a new classification of Staphylininae (Coleoptera, Staphylinidae), a rove beetle group with high lineage diversity. Systematic Entomology 45 (1): 114-127. https://doi.org/10.1111/syen.12382

Manuscript received: 23 November 2020

Manuscript accepted: 25 January 2021

Published on: 8 April 2021

Topic editor: Nesrine Akkari

Topic editor: Max Barclay

Desk editor: Pepe Fernández

Printed versions of all papers are also deposited in the libraries of the institutes that are members of the EJT consortium: Muséum national d'histoire naturelle, Paris, France; Meise Botanic Garden, Belgium; Royal Museum for Central Africa, Tervuren, Belgium; Royal Belgian Institute of Natural Sciences, Brussels, Belgium; Natural History Museum of Denmark, Copenhagen, Denmark; Naturalis Biodiversity Center, Leiden, the Netherlands; Museo Nacional de Ciencias Naturales-CSIC, Madrid, Spain; Real Jardín Botánico de Madrid CSIC, Spain; Zoological Research Museum Alexander Koenig, Bonn, Germany; National Museum, Prague, Czech Republic.

\section{Supplementary files}

Supp. file 1: The morphological dataset. https://doi.org/10.5852/ejt.2021.744.1303.3939

Supp. file 2: The concatenated morphological and molecular datasets. https://doi.org/10.5852/ejt.2021.744.1303.3941

Supp. file 3: Full topologies of all phylogenetic analyses. https://doi.org/10.5852/ejt.2021.731.1303.3943 